\title{
Terapia Ocupacional em processos econômico-sociais ${ }^{1}$
}

\author{
Maria Isabel Garcez Ghirardi
}

Doutora em Psicologia, Universidade de São Paulo - USP, Docente, Curso de Graduação em Terapia Ocupacional, Departamento de Fisioterapia, Fonoaudiologia e Terapia Ocupacional, Faculdade de Medicina da Universidade de São Paulo - FMUSP, São Paulo, SP, Brasil

\begin{abstract}
Resumo: Apresenta-se um campo de intervenções e de práticas em terapia ocupacional implicadas na questão social que busca contribuir para ampliar o alcance da experiência de acesso a bens e a direitos coletivos de populações periféricas economicamente. Propõem-se elementos de reflexão que contribuam para delinear tecnologias sociais voltadas ao fortalecimento de relações democráticas em ações de assistência social implicadas no campo do trabalho e da produção econômica. Localiza-se essa prática na fronteira entre campos de conhecimento diversos e considera-se que a terapia ocupacional agrega complexidade ao fazer quotidiano no cenário das produções socioeconômicas e do mercado de trocas. A terapia ocupacional é apresentada como uma prática que contribui para ampliar a reflexividade institucional frente a situações de precariedades socioeconômicas, a partir de um fazer comum mediado por relações de produção de bens e de valores que têm por base as capacidades produtivas da população destinatária de serviços de assistência.
\end{abstract}

Palavras-chave: Terapia Ocupacional, Assistência, Processos Econômico-Sociais.

\section{Socioeconomic processes in Occupational Therapy}

\begin{abstract}
A field of interventions and practices in occupational therapy is presented, implied with the social question that tries to enlarge the reach of the experience in accessing collective rights and goods of the peripheral economic population. Elements for reflection are proposed as a contribution to define social technologies directed to consolidate the democratic relations in social assistance actions related to the labor and economic production areas. This practice is located at the boundary of various fields of knowledge and occupational therapy aggregates complexity to the daily doing in the scenario of socioeconomic production and the market of exchanges. Occupational therapy is presented as a practice that contributes to expand the institutional reflections before the socioeconomic needs, from a common doing mediated by goods and values production relations that are based on the productive capacities of the population in need of assistance services.
\end{abstract}

Keywords: Occupational Therapy, Assistance, Socioeconomic Processes.

Autor para correspondência: Maria Isabel Garcez Ghirardi, Universidade de São Paulo - USP, Rua Cipotânea, 51, Cidade Universitária, CEP 05360-000, São Paulo, SP, Brasil, e-mail: pepag@usp.br

Recebido: 24/2/2012; Aceite final: 16/3/2012. 
Inicialmente gostaria de agradecer o convite para falar neste II Simpósio Internacional de Terapia Ocupacional Social e dizer do privilégio que é ocupar este lugar de interlocução aqui hoje e compartilhar algumas histórias profissionais. Afinal, vida é feita de histórias. Comuns e incomuns.

Quando estava para iniciar a preparação desta apresentação observei que, no momento que este II Simpósio acontece, o cenário mundial apresenta intensa crise econômica e várias manifestaçóes sociais contrárias à atual ordem global têm lugar em diversos países árabes, americanos e europeus, entre tantos outros. Faces daquilo que se conhece como questão social estão espelhadas nessas lutas sociais e a oportunidade de discutir aspectos de nossa prática profissional, neste momento, me fez refletir acerca dos modos como essa crise mundial nos toca. Considero que a terapia ocupacional constitui um campo de intervençôes implicado nas dimensões econômicas e sociais da vida quotidiana, mesmo que essas dimensões estejam, muitas vezes, eclipsadas em nossa prática profissional.

De maneira geral podemos dizer que a terapia ocupacional brasileira se organizou, historicamente, a partir de uma dimensáo clínica da assistência. Práticas profissionais esboçaram-se no universo da assistência e, particularmente, da assistência em saúde, determinando uma reflexividade profissional fortemente referida à clínica no campo da reabilitação. Essa configuração, prioritariamente clínica, ou mesmo terapêutica, constituiu um fazer profissional com foco em indivíduos que vivem em condições de desvantagem; em situação de precariedade e de vulnerabilidade física, psíquica e social. $\mathrm{O}$ fortalecimento da terapia ocupacional, no campo da assistência em saúde, propiciou uma variedade de técnicas e de métodos em áreas de reabilitação física, mental e psicossocial; açóes voltadas a processos de desinstitucionalização; e cuidados clínicos a grupos socialmente estigmatizados. Instituem-se práticas e discussóes a partir do campo da saúde, em terapia ocupacional, de tal forma que, mesmo quando as ações profissionais de assistência se expandem em direção a práticas do campo da educação, por exemplo, a matriz da ação terapêutica ocupacional é a relação clínica e dual.

Há vinte anos, num texto em que criticava o modelo reducionista de reabilitação, Denise Barros (1991) nos provocava a refletir sobre o sentido da reabilitaçáo que se praticava em terapia ocupacional. Em última instância, a colega questionava as açôes de reabilitação e perguntava: reabilita-se o quê? Para quê, se não se consideram as contradiçóes da vida quotidiana no processo de reabilitação? A autora lembrava, com o poeta, que a vida é real e de viés, e que não está restrita à lógica da reabilitação. $\mathrm{O}$ real é coletivo e os vieses também o são, dizemos nós, quando nos damos conta de que, parâmetros clínicos, embora respondam às demandas do campo da assistência em saúde, não se sustentam em relação a práticas em terapia ocupacional interessadas em contribuir para a superação de limitaçóes que são impostas mais pela questão social do que pela questão da saúde.

A lógica da clínica tende a traduzir fenômenos sociais em termos e em categorias que compóem o vocabulário e o conhecimento no campo da saúde. Apenas para citar um exemplo, veja-se a discussão em torno do direito ao trabalho. Trabalho é uma categoria da vida social, um direito social que, entretanto, em terapia ocupacional é abordado na prática assistencial a partir da retórica clínica (pessoas com deficiência; em sofrimento psíquico, entre outras). Ao esvaziar as dimensões sociológicas e econômicas do mundo do trabalho, tende-se a reduzir a complexidade social que caracteriza o trabalho enquanto um direito coletivo e transformar esse suposto direito de todos em obrigação de alguns.

Há uma dimensão social da vida e do fazer quotidiano, que escapa à lógica clínica ou terapêutica da assistência individual. Essa dimensão diz respeito às relaçóes sociais que se vive no dia a dia, no convívio quotidiano e em realidades sociais variadas (CERTEAU, 1990). Essa dimensão de trocas, de encontros e desencontros, coloca a assistência em terapia ocupacional diante de uma fronteira profissional que se refere ao que há de comum na vida, a dimensóes coletivas e institucionais, culturais e econômicas que sustentam a organização e a participação social. Ao abordar a produçấo dos laços sociais, as instituiçóes e o tecido normativo da vida social, a terapia ocupacional é convidada a deixar de lado a retórica da falta e da exceçáo individuais e abordar a positividade da participação social ao enfatizar as formas sistêmicas de compartilhamento do fazer em coletivos de trabalho, de lazer e de transporte, por exemplo.

Em síntese, trata-se de propor uma terapia ocupacional interessada em descrever formas de intensificar a polifonia, a participação em situações comuns, nos fazeres que compóem o quotidiano da esfera social da vida, numa abordagem menos personalista e mais sistêmica do fazer. Essa dimensão coletiva, de busca de semelhanças no fazer ao invés de diferenças no ser ou no estar, de positividades coletivas, ao invés de negatividades individuais, demanda um deslocamento na prática da terapia ocupacional ao reconhecer que, de um modo ou de outro, se vive em sociedade e que a dimensão participativa e social da vida pública não é redutível à 
esfera individual e privada dos padeceres quotidianos. Há o reconhecimento de que as pessoas organizam formas de fazer e, contemporaneamente, se organizam em torno de fazeres necessários à vida daquela coletividade.

Aliás, a questão social, de que trata esta mesa, diz respeito a essa dimensão e é importante interrogar a maneira como a terapia ocupacional está implicada nessa questão. Vale lembrar que o próprio conceito de questão social foi inicialmente formulado na Europa do século XIX, no momento da revoluçáo industrial e que essa foi a

[...] designaçáo usada pelas elites para descrever o contexto do surgimento de inúmeras iniciativas populares em reação às condiçôes de trabalho e vida da industrialização e do capitalismo liberal (FERREIRA, 2008, p. 31).

A terapia ocupacional social tem proposto uma prática profissional que escapa à dimensão da clínica da saúde, por mais avançada que essa clínica possa ser. Essa abordagem da terapia ocupacional social coloca em relevo a esfera pública e comum, a dimensão coletiva da vida social quotidiana que se dá no encontro entre diferenças de várias ordens, de gênero, de classe, de culturas, entre tantas outras e que determinam variaçóes no modo de estar e de fazer mundos. À semelhança do fenômeno das pororocas, em que águas do rio e do mar se misturam para transformarem-se numa outra coisa que não é a simples somatória de duas águas, a terapia ocupacional social interessa-se contemporaneamente pelas multiplicidades e pelas condiçóes singulares que levam à criaçáo de lugares de encontro e de trocas, sustentadas por uma diversidade de fazeres. Estabelece uma gramática que provoca a expansão do imaginário profissional ao discutir a ocupação coletiva de lugares públicos, num deslocamento da prática que focaliza aquilo que é comum às questóes sociais. Questôes que são irredutíveis a formas de relação terapêutica ou clínica (com grupos ou indivíduos específicos), mas que trata de viabilizar o encontro de diferenças radicais, no processo de produção de bens e de valores sociais, sem pretender adaptar este ou aquele sujeito a condiçôes pré-estabelecidas.

Busca-se uma condição do fazer coletivo em que eventuais adaptaçóes necessárias incorram sobre o ambiente produtivo de forma geral, ou seja, uma reordenação do fazer, em função de diferenças e de positividade na participação democrática. Para tanto, é importante resgatar a dimensão relacional, múltipla, social do fazer e desenvolver tecnologias que favoreçam um terreno em que diversos níveis de complexidade do fazer (que vão desde aqueles individuais e especiais àqueles que são coletivos e comuns) sejam contemplados e ativados num percurso metodológico interessado em intensificar processos de participaçáo em lugares de produçãao econômica.

Empreender a vida social como matéria de cuidado, transformá-la, depende de práticas quotidianas e de ações coletivas que instituem uma forma de produção de bens de mercado e de serviços de assistência e que, simultaneamente, produzem transformaçóes relacionais e coletivas nessa mesma produção. É um compromisso quotidiano e coletivo de superaçáo de formas de dominaçáo e de poder que fazem com que participação seja sempre um problema do outro, numa lógica moralizante que faz crer que existem recursos, o outro é que não adere às propostas de assistência (DE LEONARDIS, 1990).

Abordar o trabalho, na perspectiva da terapia ocupacional em processos econômicos e sociais, pressupóe reconhecer que o trabalho é central naquilo que se conhece como questão social. Assim, a meu ver, o desafio que enfrentamos é aquele de construir percursos metodológicos em terapia ocupacional que contribuam para criar lugares de trabalho que sejam abertos a todos os que necessitam trabalhar, tendo como pressuposto o fato de que um ambiente de trabalho polifônico cria valor social e que a dimensão coletiva impede a reificação do trabalho ou, pior, da renda, como ocorre nas práticas moralizantes, em que o trabalho é visto como um bem em si mesmo. O fio que interessa acompanhar em terapia ocupacional em processos econômico-sociais diz respeito a esse deslocamento analítico, ou seja, priorizam-se as dimensões coletivas e comuns do fazer, mais do que a relação clínica individual e a dimensão particularista da ação. Trabalhar é um direito coletivo, não é uma necessidade especial. É outra história. É uma história comum, embora não seja banal. E, por vezes, seja mesmo brutal.

O deslocamento que a terapia ocupacional em processos econômico-sociais tem procurado ativar no campo teórico e prático da profissão diz respeito a reconhecer as dimensôes sociológicas, econômicas, coletivas e as contradiçóes que definem o mundo do trabalho. Assim, as intervençóes de terapia ocupacional em processos econômico-sociais pautam-se pela observação do lugar coletivo do trabalho, em suas dimensões de relações de poder, de contradições e de determinaçóes sociais que se estabelecem no processo de organização do trabalho e no contexto quotidiano uma produção coletiva. Diante da evidente dimensão coletiva e política do mundo do trabalho, a terapia ocupacional em processos econômico-sociais busca estabelecer percursos de intervenção que superem a retórica da subjetividade e a carga das derivaçóes morais e meritocráticas que dela podem decorrer, para inventar 
outra gramática institucional que favoreça formas de análise e de intervenção que contribuam, na prática, para o alargamento das esferas de participação social, num mundo em que valores de produção remetem à potência individual, à flexibilização do trabalho que impóe perda de direitos sociais e à exclusão laboral daqueles que não se adaptam às novas formas de gestão do trabalho.

Exercer o direito ao trabalho é um desafio coletivo, sobretudo quando os índices de desocupação, a flexibilização e as formas globalizadas de organização do trabalho transformam esse direito em privilégio, é necessário investir em ações coletivas que permitam redesenhar percursos de valorização das capacidades desses muitos excluídos do mercado produtivo. Ao abordar processos econômico-sociais, a terapia ocupacional entende que um coletivo de produção não é um lugar onde uma série de sujeitos se encontra para discutir seus problemas individuais e busca apoio para superá-los, de forma a poder - por exemplo - gerar renda e superar a miséria econômica. Um coletivo de produção é antes de tudo um lugar em que a reflexividade comum pode ser ativada e uma condição social pode ser criticada e eventualmente superada no encontro de soluçôes coletivas que escapam da lógica liberal e individualista de produção econômica (GIDDENS, 1990).

Percursos metodológicos atentos aos níveis de complexidade do fazer relacional e institucional, que observam e descrevem os elementos que sustentam a ação coletiva, subsidiam intervençôes que buscam fortalecer lugares coletivos democráticos e participativos nos quais se produza valor social ao gerar trabalho e renda. Assim, a partir de pressupostos epistemológicos que consideram as dimensóes sociais de intervençóes em terapia ocupacional, propóem-se elementos para um campo de reflexão e de investigação das bases informativas da ação terapêutica ocupacional e de seu compromisso ético e político. Estratégias de intervenção em processos econômico-sociais pautam-se por investimento na capacidade de auto-organizaçáo coletiva e na criatividade individual para definir percursos participativos que criam condiçóes para que se ultrapasse a posição de destinatário de açôes de assistência e se avance em direção à posição de produtor de bens e de valores sociais.
Vale lembrar, em tempos de movimento verde, de defesa ecológica, que ambientes ricos são aqueles com grande diversidade de organismos vivos e produtivos; esta apresentação afina-se com a tese de que a diversidade enriquece o meio e que um ambiente variado permite que limitaçóes e capacidades individuais sejam reguladoras do sistema produtivo e relacional coletivo. Por outro lado, essa é uma questão para diversas profissóes que compóem o campo da assistência social e que debatem os limites das políticas públicas de assistência, tendo como foco os destinatários dessas açóes, com vistas a ultrapassar o processo de dependência dos serviços de referência ao ativar o direito de voz dos destinatários dessas açôes.

Recentemente pudemos concluir um trabalho de pesquisa que buscou discutir fatores de adesáo a um projeto de geração de renda desenvolvido por uma instituição social. Todo o trabalho de pesquisa foi desenvolvido sobre a análise do trabalho a ser realizado com vistas a ganho econômico. Discutimos a venda de revistas de rua como um trabalho complexo, com toda a cadeia envolvida no processo de produção e de circulação da revista. Evitou-se assim a discussão moralizante de que o recurso existe e o outro é que não adere. Mas essa é outra história, para ser contada em outra ocasião!

Assim, finalmente, podemos dizer que as questôes do mundo ocidental contemporâneo dizem, sim, respeito à terapia ocupacional, sempre que esta pretenda contribuir para o fortalecimento de sociedades polifônicas e democráticas.

\section{Referências}

BARROS, D. D. Habilitar-reabilitar...o rei está nu? Revista de Terapia Ocupacional da Universidade de São Paulo, v. 2, n. 2, p. 100-104, 1991.

CERTEAU, M. L'invention du quotidien. Paris: Gallimard, 1990.

FERREIRA, S. A questão social e as alternativas da sociedade civil no contexto das novas formas de governação. Ciências Sociais Unisinos, v. 44, n. 1, p. 28-38, 2008.

GIDDENS, A. As consequências da modernidade. Tradução de Raul Ficker. São Paulo: UNESP, 1990.

DE LEONARDIS, O. Il terzo escluso: L'istituzioni come vincoli e risorse. Milão: Feltrinelli, 1990.

\section{Notas}

${ }^{1}$ Este texto é parte da apresentação que integrou o II Simpósio Internacional de Terapia Ocupacional Social, em outubro de 2011, e compôs a mesa, Diálogos sobre o desenvolvimento da Terapia Ocupacional implicada nas Questóes Sociais no Brasil e no Mundo. 